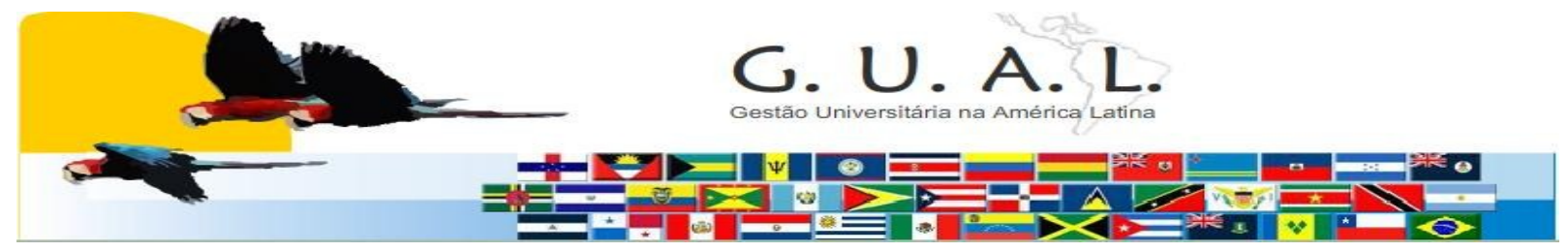

ISSN 1983-4535

\title{
AVALIAÇÃO DAS POSSIBILIDADES DE IMPLANTAÇÃO DO BALANCED SCORECARD EM INSTITUIÇÕES DE ENSINO SUPERIOR
}

\section{EVALUATION OF THE POSSIBILITY OF IMPLEMENTING THE BALANCED SCORECARD IN INSTITUTIONS OF HIGHER EDUCATION}

Andreia Luciana da Rosa Scharmach, Doutora Universidade do Contestado - UnC andreia@mfa.unc.br

Maria José Carvalho de Souza Domingues, Doutora Universidade Regional de Blumenau - Furb mariadomingues@furb.br

Carlos Eduardo Carvalho, Doutor Universidade do Contestado - UnC carloseduardo@unc.br

Nelson Santos Machado, Doutor Universidade do Oeste de Santa Catarina - Unoesc

Recebido em 15/fevereiro/2011 nelson.machado@unoesc.edu.br

Aprovado em 20/abril/2012

Sistema de Avaliação: Double Blind Review

Esta obra está sob uma Licença Creative Commons Atribuição-Uso. 


\title{
RESUMO
}

O aumento da competição entre as Instituições de Ensino Superior - IES exige que os gestores destas instituições reconheçam a importância da busca de padrões de eficiência em sua gestão. Nesse sentido este trabalho busca contribuir com estudos sobre as possibilidades e limitações da aplicação do Balanced Scorecard em IES do sul do Brasil. Para tanto se buscou identificar as diretrizes existentes na instituição, a compreensão de informações dos gestores e por fim, apresentar diretrizes para aplicação do modelo de gestão. A pesquisa aconteceu em duas fases: a primeira fase foi qualitativa, com delineamento exploratório no qual foram realizados procedimentos de pesquisa documental e de campo, realizada através de entrevistas com os gestores estratégicos. A segunda fase foi quantitativa descritiva com aplicação de questionários aos gestores estratégicos e táticos da instituição. Os resultados demonstram que a Universidade pesquisada possui algumas diretrizes preliminares para aplicação do BSC como a visão, a missão e informações sobre o ambiente organizacional. Os gestores percebem a importância da implementação de um modelo de gestão que delineie ações futuras para a competitividade da instituição, mas com adaptações considerando as características peculiares deste tipo de organização. Os resultados ainda apontam que a universidade estudada possui mais possibilidades que limitações para a aplicação do modelo.

Palavras-chave: Gestão estratégica. Balanced scorecard. Instituições de ensino superior.

\begin{abstract}
Increased competition between Universities requires that managers of these institutions recognize the importance of seeking efficiency standards in its management. In this sense this work seeks to contribute to studies on the possibilities and limitations of applying the Balanced Scorecard in university of southern Brazil. The study had the goal to identify existing guidelines in the institution and the management informations and finaly provide guidelines for implementation of the management model. The research was done in two phases: the first phase was qualitative, exploratory design with which the procedures were performed archival research and field, through interviews with strategic managers. The second phase was quantitative descriptive with questionnaires applied to strategic and tactical management of the institution. The results demonstrate that the University has researched some preliminary guidelines for implementation of the BSC as the vision, mission and information about the organizational environment. Managers realize the importance of implementing a management model that outlines actions for the future competitiveness of the institution, but with adaptations considering the peculiar characteristics of this type of organization. The results also indicate that the university studied has more possibilities than limitations to the application of the model.
\end{abstract}

Keywords: Strategic management. Balanced scorecard. Universities. 


\section{AVALIAÇÃO DAS POSSIBILIDADES DE IMPLANTAÇÃO DO BALANCED SCORECARD EM INSTITUIÇÕES DE ENSINO SUPERIOR}

\section{INTRODUÇÃO}

A expansão da educação superior aliada à busca da qualidade na prestação de serviços fazem com que as IES busquem um melhor preparo em sua gestão. Estas instituições buscam padrões de eficiência de gestão para obter maior competitividade na atividade que atuam.

O ambiente competitivo ocasionado pela rápida expansão das IES é um dos principais fatores que indicam a necessidade da gestão eficiente. A rápida expansão das IES é ocasionada, além de outros aspectos, pela meta Educacional do Plano Nacional de Educação PNE, em ofertar ensino superior para pelo menos 30\% dos jovens brasileiros até o final da primeira década do século XXI (BRASIL, 2001).

Quanto à busca da qualidade, o cenário fundamenta-se no cumprimento das necessidades e na satisfação de seus stakeholders. De forma particular, como em outras organizações, as IES necessitam estar focadas também na satisfação de seus clientes, pois é somente pelo atendimento de suas necessidades que se cumpre os objetivos da organização.

Uma vez os clientes satisfeitos pelo atendimento dos seus propósitos, as IES irão gerar valor para a sociedade. A sociedade necessita de cidadãos conscientes e profissionais qualificados para atender seus anseios sociais e profissionais.

Meyer e Lopes (2008) explicam que nas organizações de educação, por sua relevância como instituição social, a gestão tem uma importância maior por preparar pessoas para o trabalho e para a vida em sociedade.

Diante a expectativa da sociedade e das exigências legais sobre a qualidade e eficiência que as IES brasileiras devem oferecer aos profissionais que esta formando, é que estas instituições se submetem a uma diversidade de avaliações e regulamentações.

Estas avaliações são as aplicadas pelo governo federal através do Ministério da Educação e Cultura - MEC. São utilizadas para a regulamentação e supervisão da qualidade dos serviços que as IES estão oferecendo, como exemplo, a avaliação institucional, a avaliação de cursos e o plano de desenvolvimento institucional.

O cumprimento das regulações, focando a qualidade dos serviços prestados, ora exigidos por seus stakeholders, traz oneração nas atividades destas organizações, e com isso, mais motivos para a busca de padrões eficientes para sua gestão objetivando a competitividade.

Cavalieri, Macedo-Soares e Thiollent (2004) comentam que as universidades brasileiras já começaram a adotar estratégias e práticas de melhoria contínua, objetivando uma 
gestão mais eficiente diante da pressão competitiva ditada pela globalização e também por consumidores exigentes e bem informados.

Uma gestão com foco em resultados de sucesso tornando a organização competitiva pela excelência dos serviços prestados por meio da satisfação das necessidades requisitadas pelos stakeholders, direciona à aplicação e uso da gestão estratégica.

Herrero Filho (2005, p. 3) explica que a essência da gestão estratégica efetiva é "elaborar por meio de uma abordagem inovadora e criativa, uma estratégia competitiva que assegure o êxito da organização nos negócios atuais, ao mesmo tempo em que constrói competências essenciais necessárias para o sucesso nos negócios de amanhã."

Um campo conceitual e metodológico para a operacionalização e controle da gestão estratégica se faz necessário. A operacionalização e os controles precisam de instrumentos, técnicas, processos e ferramentas. Por isso se coloca neste trabalho as técnicas, metodologia e controles que resultam da aplicação do Balanced Scorecard - BSC, como um modelo de gestão integrada, com a utilização de estratégias voltadas para resultados de sucesso.

O BSC considera que não basta as organizações administrarem apenas seus ativos com base em relatórios financeiros e contábeis ou em seus bens físicos. Existe também a necessidade da elaboração de planejamento que institucionalize uma missão e visão de futuro para a organização, suas formas de desenvolvimento de processos, de satisfação de seus clientes e no aprendizado e crescimento de seus colaboradores.

$\mathrm{Na}$ busca de informações em bases bibliográficas científicas sobre o uso do modelo de gestão BSC em IES sem fins lucrativos, é perceptível ainda a carência sobre o assunto.

Keller (1983) observa que não há teorias sobre gestão universitária. Aponta que ela está sendo construída por investigações desenvolvidas por estudiosos na área de gestão universitária, bem como pela prática dos gestores universitários quando buscam soluções aos problemas enfrentados diariamente.

Em uma visão mais recente, de Meyer e Lopes (2008), os autores afirmam que a gestão educacional ainda é um campo de estudo recente e seu conteúdo abarca um conjunto de conhecimentos teóricos e uma dimensão prática.

Diante do contexto teórico limitado de estudos científicos sobre gestão de IES e do contexto prático de gestão das IES, é que se busca através do desenvolvimento desta pesquisa mostrar possibilidades e limitações da aplicação do modelo de gestão BSC em uma IES sem fins lucrativos, localizada no sul do país. 
Para o desenvolvimento desta pesquisa foi necessário estudar o modelo do Balanced Scorecard, conforme o contexto de entendimento e de prática; identificar quais as diretrizes existentes para aplicação do BSC na IES estudada; compreender as informações dos gestores da IES para a aplicação do BSC e por fim propor diretrizes para aplicação do BSC na IES em estudo.

\section{INSTITUIÇÕES DE ENSINO SUPERIOR COMO ORGANIZAÇÕES COMPLEXAS}

Morgan (1996) explica que é difícil ter uma definição exata e específica de uma organização devido à diversidade e exclusividade de suas características, que as tornam sem uma evidência científica única para todas, considerando por meio de seus estudos que as organizações são complexas com características peculiares.

Numa visão organizacional de instituições de ensino, Hardy e Fachin (2000) evidenciam que os principais modelos teóricos de governo acadêmico são: o burocrático; o colegiado; o político e a anarquia organizada.

Cohen e March (1974) enfatizam que a predominância na tomada de decisões nas universidades é a anarquia organizada, ou seja, cada decisão é tomada de forma autônoma pelos seus integrantes, desde os legisladores até os discentes. Justificam essa predominância pela ausência de coordenação e controle nestas instituições.

Baldrigde (1983) percebe as IES sem fins lucrativos, como instituições caracterizadas por objetivos difusos. Tem sua natureza política com base em grupos de interesses e uma estrutura complexa. Ainda as coloca como muito sensíveis às forças do ambiente externo.

As IES são consideradas complexas por realizarem tarefas diversas - ensino, pesquisa e extensão, que impõem métodos de trabalhos diferentes dos outros tipos de organização. Tais diferenças estão na natureza dos trabalhos, na tecnologia utilizada, nas pessoas que trabalham na organização e em seus clientes. Baldridge (1983) coloca algumas das principais características das IES: suas metas são vagas e ambíguas; têm uma clientela com necessidades distintas e complexas, o que proporciona problemas de tecnologia; predominância de pessoal especializado; são vulneráveis as forças e pressões externas.

Meyer Jr. (2007) agrega além dos de Baldridge (1983), outros elementos a essas particularidades, como a natureza intangível dos produtos que resultam das suas atividades, processo decisório, participação fluida, não linearidade de produção e dificuldade de avaliar o valor agregado. 
Meyer e Murphy (2003, p. 182) comentam que a complexidade das IES requer um "[...] novo tipo de administração, mais racional e que privilegie critérios de eficiência e de eficácia organizacionais, leveza estrutural, produtividade, competitividade, sem perder de vista o papel acadêmico e social das instituições.”.

Diante às características complexas e ambíguas BALDRIDGE (1983), HARDY E FACHIN (2000), MEYER JR. (2007), leva à seguinte consideração de Weick apud Meyer Jr. (2007).

As teorias tradicionais de administração quando aplicadas no contexto da escola tendem a falhar devido a quatro pressupostos implícitos nessas abordagens gerenciais e que contribuem para esse fracasso: 1) existência de um sistema racional auto corretivo entre pessoas, que trabalham de forma altamente interdependente; 2) consenso sobre os objetivos e os meios para atingi-los; 3) coordenação por meio da disseminação da informação; 4) previsibilidade dos problemas e das respostas a esses problemas. (WEIK, 1982 apud MEYER Jr., p. 256, 2007).

Meyer e Lopes (2008) acrescentam que quando as organizações escolares não apresentam estas características, os modelos convencionais não se aplicam na realidade destas organizações. Portanto se faz necessária essas importantes observações como antecedentes da aplicação de modelos de gestão em IES.

\subsection{Gestão estratégica em IES}

Atualmente o tema gestão da estratégia, tornou-se um fator de grande importância para a competitividade das organizações dos mais diversos setores, como instituições sem fins lucrativos, entidades públicas e governos. Essas organizações estão cada vez mais preocupadas em garantir-se na atividade em que atuam, assumindo objetivos claros junto aos seus stakeholders (MANGELS, 2005).

A estratégia é o padrão ou plano que integra as principais metas, políticas e seqüências de ação da organização em um todo coeso. Uma estratégia bem formulada ajuda a organizar e alocar os recursos de uma organização em uma postura única e viável, baseada em suas competências e deficiências internas relativas, mudanças antecipadas no ambiente e movimentos contingentes por parte dos oponentes inteligentes. (MINTZBERG et al., 2008, p. 28.)

Segundo Bryson e Alston (1996), com a utilização da gestão estratégia, as organizações podem examinar o ambiente em que esta operando; explorar os fatores e tendências que afetam os negócios; buscar e designar meios de cumprir sua missão; formar estratégias que demonstrem seus deveres e discursos; encontrar maneiras de fazer análises e 
trabalhos constantes referentes a sua missão, seus produtos e serviços, seus custos, seus processos administrativos e organização.

Weik (1976) evidencia que a maioria das instituições de ensino tem um gerenciamento amador. Isso gera uma organização com pouca articulação em suas ações de gestão, ocasionada pela falta da relação de causa e efeito entre as tomadas de decisões e suas ações.

A deficiente habilidade gerencial e a pequena flexibilidade estrutural das IES, deixam a desejar, quando são necessários o estabelecimento de mudanças rápidas para adequar-se ao ambiente em que estão e aproveitar as oportunidades que este ambiente oferece. Como isso acaba dificultando a administração com base no planejamento na estratégia destas instituições (PEREIRA; MELO; CUNHA, 2008). Meyer e Lopes (2008) complementam essa ideia quando afirmam que um dos desafios da gestão é a determinação de objetivos de longo prazo e a dificuldade dos produtos e resultados da educação.

Bryson (2004) considera que organizações como as IES sem fins lucrativos, precisam realizar avaliações de seus cenários ambientais na busca de oportunidades e direcionamentos voltados ao cumprimento de sua missão.

A capacidade de respostas às exigências externas é uma das formas de sobrevivência das universidades. Para tanto as universidades necessitam de um reexame de suas estruturas e processos reconhecidamente obsoletos e ultrapassados, e no desenvolvimento de capacidade estratégica de adaptação e sobrevivência num contexto tão desafiante como o vivido pelas escolas e universidades atualmente (BIRNBAUM, 1988).

Importante ressaltar nas palavras de Meyer Jr (2007), que a gestão das instituições de ensino devem ser realizadas sempre levando em consideração suas características peculiares. Modelos gerenciais criados para funcionar em organizações lineares e mecanicistas estão sendo largamente utilizados na gestão escolar sem considerar que o contexto empresarial se distingue bastante da realidade da escola como organização complexa. “ [...] são as características especiais das instituições universitárias, [...], que irão requerer uma atenção especial dos seus administradores. Negligenciá-las implicaria em comprometer a eficácia do trabalho do administrador." (ALMEIDA, 2003, p. 180).

\subsection{Balanced scorecard em IES}

O Balanced Scorecard - BSC é um modelo de gestão integrada, desenvolvido por Robert Kaplan e David Norton. A proposta dos autores através do desenvolvimento do BSC é de que as organizações além de mensurarem os indicadores financeiros (tangíveis) também o 
fizessem com os não financeiros (intangíveis), como clientes e conhecimento de seus colaboradores, sempre de forma a criar valor no processo, produto e/ou serviço.

O BSC complementa as medidas financeiras com medidas intangíveis que impulsionam o desempenho futuro. Os objetivos e as medidas são derivados da visão e da estratégia da organização para termos operacionais, que focalizam o desempenho nas perspectivas de estabelecimento de: metas financeiras, dos clientes, dos processos internos, e de aprendizado e crescimento (KAPLAN; NORTON, 1997).

Medidas na visão do BSC, descritas por Herrero Filho (2005, p. 39) são os indicadores que "[...] permitem avaliar até que ponto as atividades e ações que deveriam estar sendo desenvolvidas na organização estão progredindo, sendo completadas, ou ainda merecendo o foco e a atenção dos colaboradores da organização."

O BSC não pode ser entendido apenas como conjuntos de indicadores críticos ou fatores chaves de sucesso, mas sim a composição de uma cadeia articulada de medidas e objetivos lógicos que se reforcem reciprocamente, que funcionem como um conjunto complexo de relações de causa e efeito (devem permear as quatro perspectivas) e que seja possível a combinação de medidas de resultado e vetores de desempenho, pois as medidas de resultados sem os vetores de desempenham não comunicam a forma que os resultados são alcançados.(KAPLAN; NORTON, 1997).

A utilização do Balanced Scorecard em organizações sem fins lucrativos foi fortalecida após 1996, quando o conceito se ampliou e adaptou-se para atender às peculiaridades dessas organizações. A principal dessas adaptações está em substituir a lucratividade pela missão dessas organizações na definição de seus scorecards (KAPLAN; NORTON, 2000).

Niven (2005) explica a importância da aplicação do BSC em instituições sem fins lucrativos diante às rápidas mudanças de seus cenários, principalmente no que se refere a concorrência e ao grau de exigência que seus clientes vêm mostrando. Complementa que em situações como estas as organizações são forçadas a rever suas práticas gerenciais em busca de métodos que assegurem sua continuidade no mercado.

\section{MÉTODO}

O método utilizado para o desenvolvimento da pesquisa caracteriza-se em duas partes ou momentos distintos: a primeira como qualitativa com objetivo exploratório, e a segunda como quantitativa com objetivo descritivo. 
A abordagem qualitativa de um problema, justifica-se por ser uma forma adequada para entender a natureza de um fenômeno social e afirma que a pesquisa qualitativa pode ser "caracterizada como a tentativa de uma compreensão detalhada dos significados e características situacionais [...]” (RICHARDSON, 1999, p. 90). A caracterização da pesquisa como exploratória normalmente ocorre "quando há pouco conhecimento sobre a temática a ser abordada.” (BEUREN, 2006, p. 80).

Por meio da pesquisa qualitativa exploratória foi estudado:

a) o modelo do BSC conforme o contexto de entendimento e prática - através de pesquisa bibliográfica em livros, revistas, sites de domínio público, artigos, teses e dissertações;

b) a identificação das diretrizes existentes para a implementação do BSC - por meio de pesquisa documental no PDI, Avaliação Institucional, estatutos, normas, leis, sites.

c) a compreensão das informações dos gestores da universidade para a aplicação do BSC - por meio de pesquisa de campo, com entrevistas aplicadas a uma amostra escolhida intencionalmente a 14 integrantes da alta administração ( 7 gestores estratégicos da área acadêmica e 7 gestores estratégicos da área administrativa) dos cinco Campi/Unidades da universidade. Para a entrevista foi elaborado um roteiro semi estruturado com base na teoria do BSC.

Após as transcrições das entrevistas, os dados foram analisados pela análise de conteúdo. Segundo Bardin (1979, p.31) a análise de conteúdo é "um conjunto de técnicas de análise das comunicações visando obter, através de procedimentos sistemáticos e objetivos de descrição do conteúdo das mensagens, indicadores que permitam inferir conhecimentos relativos às condições de produção/recepção (variáveis inferidas) dessas mensagens.".

A técnica utilizada da análise de conteúdo foi a análise por categoria, e para formar a categoria foi utilizada a análise temática. Segundo Richardson (1999) a análise por categoria se baseia na decodificação de um texto em diversos elementos, os quais serão classificados para formar elementos analógicos. Para formar a categorização pode ser utilizada a análise temática, a qual consiste em isolar os temas de um texto coletado e extrair as partes utilizáveis e correlacionáveis ao problema da pesquisa, para permitir a comparação com outros textos escolhidos da mesma forma.

A pesquisa quantitativa, segundo Malhotra (2001), procura quantificar os dados e aplica formas estatísticas para análise. Quanto à caracterização descritiva, segundo Gil (2002, p. 42) tem como "objetivo primordial a descrição das características de determinado fenômeno $[\ldots] . . "$ 
A pesquisa quantitativa descritiva foi realizada para apoiar na identificação e compreensão das informações para a aplicação do BSC.

Foi realizada pela pesquisa de campo, por meio de questionário fechado formulado com base na teoria do BSC, pelo método da escala de Likert. O questionário foi aplicado a uma amostra intencional de 57 integrantes da gestão estratégica e tática dos cinco Campi/Unidades da universidade estudada. Os gestores respondentes gerenciam setores dos Campi da universidade que concernem às quatro perspectivas do BSC. Obteve-se retorno de 42 questionários respondidos.

As respostas do questionário aplicado foram interpretadas por análises estatísticas. Iniciaram pelo próprio questionário aplicado logo após a coleta e tabulação dos dados. $\mathrm{O}$ procedimento adotado para esta análise foi o de recorrer a um teste de confiabilidade denominado Alfa de Crombach. À medida que o número de questões aumenta, há necessidade de maior conhecimento de suas inter-relações. A confiabilidade que varia de 0 a 1 , tem nos valores de 0,60 a 0,70 o limite inferior de aceitabilidade (HAIR, et. al., 2005). A efetivação do teste apontou para uma confiabilidade de 0,8804 , portanto considerado um instrumento confiável diante os limites inferiores estabelecidos para aceitabilidade.

Para a análise das respostas obtidas do questionário foi utilizado o software estatístico SPHINX ${ }^{\circledR}$, que proporcionou os percentuais de respostas, médias ponderadas e desvio padrão.

Os dados oriundos do questionário foram incorporados com os dados obtidos das entrevistas nas três categorias temáticas formuladas, no sentido de apontar as limitações e possibilidades da aplicação do BSC na IES estudada em cada uma das categorias temáticas.

\section{ANÁLISE E INTERPRETAÇÃO DOS DADOS}

No sentido de apontar as possibilidades e limitações da universidade estudada para a aplicação do BSC em sua gestão, estão descritas na sequência situações de resultados percebidos como possibilidades e/ou limitações quanto: a identificação das diretrizes existentes para aplicação do BSC na universidade estudada; na compreensão das informações dos gestores da IES para a aplicação do BSC; e, na proposição das diretrizes para aplicação do BSC na IES estudada. 


\subsection{Diretrizes existentes para aplicação do BSC}

Segundo Kaplan e Norton (1997), algumas das diretrizes básicas para a aplicação do modelo de gestão em qualquer tipo de organização é ela possuir estabelecida sua visão e missão.

A IES estudada já é detentora de uma missão e visão, que relacionam-se as duas primeiras diretrizes exigidas para a aplicação do BSC. A missão e visão da instituição foram extraídas do Plano de Desenvolvimento Institucional da IES em questão.

Outra diretriz importante colocada pelos criadores do BSC, é que antes de transformar as estratégias em ação, se faz necessário uma análise da organização para identificar quais são seus pontes fortes, suas fragilidades, suas oportunidades e ameaças. Essa análise ambiental dará origem a fatores chave para o sucesso da organização de onde poderá originar-se os temas e objetivos estratégicos para a organização no sentido de cumprir sua visão e missão que estão direcionadas ao cumprimento da estratégia a longo prazo (KAPLAN; NORTON, 1997).

A diretriz de coleta e análise de informações do ambiente da organização, já existe na IES estudada e são encontradas em sua Avaliação Institucional do ano de 2009.

\subsection{Compreensão das informações dos gestores para aplicação do BSC na IES estudada}

As informações identificadas nas pesquisas de campo estão apresentadas neste capítulo em conformidade com as categorias temáticas elaboradas no método da pesquisa, quais sejam: entendimento, necessidade, importância e situação da gestão estratégica na universidade estudada compreensão das informações futuras e situacionais para proposição das diretrizes para aplicação do BSC; e, oportunização da aplicação do BSC na instituição estudada.

A compreensão das informações contidas em cada categoria temática tem origem nas respostas das entrevistas (alta gestão) e do questionário (alta e média gestão). Kaplan e Norton (1997) citam que é fundamental que as primeiras ações para a elaboração e aplicação do BSC nas organizações sejam originadas da alta gestão.

Segue a análise das informações coletadas, iniciando pela primeira categoria temática. 


\subsubsection{Entendimento, necessidade, importância e situação da gestão estratégica na IES estudada}

A primeira análise é sobre o entendimento dos gestores estratégicos sobre a gestão estratégica. Para tanto foi realizada a seguinte indagação: qual o entendimento que tem sobre a formulação e aplicação de estratégias de gestão alinhadas à missão e visão na Universidade?

A análise de conteúdo aponta que o entendimento dos gestores estratégicos quanto a formulação de estratégias alinhadas a missão e a visão estão muito próximos, não havendo uma interpretação que deixe dúvida de que algum de seus gestores não tenha um entendimento sobre a gestão estratégica. Herrero Filho (2005) comenta que o pensamento estratégico deve ser entendido e estimulado entre as pessoas que trabalham na organização. Apesar de haver um entendimento muito próximo entre os gestores, há uma diversidade de opiniões quanto a existência deste alinhamento na Universidade em questão.

A compreensão desta informação leva a crer que mesmo os dirigentes tendo funções diferentes dentro da instituição (acadêmicas e administrativas), têm opiniões muito próximas sobre este quesito. Este fato torna uma possibilidade para a aplicação do BSC na Universidade Estudada.

Já quanto eles divergirem sobre se existe o alinhamento da missão e das estratégias na universidade, foca a necessidade de uma discussão sobre o assunto e principalmente da obtenção de um consenso entre os dirigentes para que futuramente possa ser trabalhado o modelo de gestão, sem ser este fato uma limitação.

Fernandes e Berton (2005) observam que o consenso absoluto entre os gestores para a implementação de um modelo de gestão é muito difícil de obter. O que geralmente acontece é uma aceitação em detrimento a opinião dos pares.

Quando os gestores respondentes foram deparados no questionário sobre sua concordância com a afirmação de que: as estratégias de gestão definidas para a instituição têm um alinhamento com sua missão e visão, obteve-se $53,6 \%$ das respostas na escala de "concordo" e "concordo totalmente", conforme demonstradas no gráfico 1.

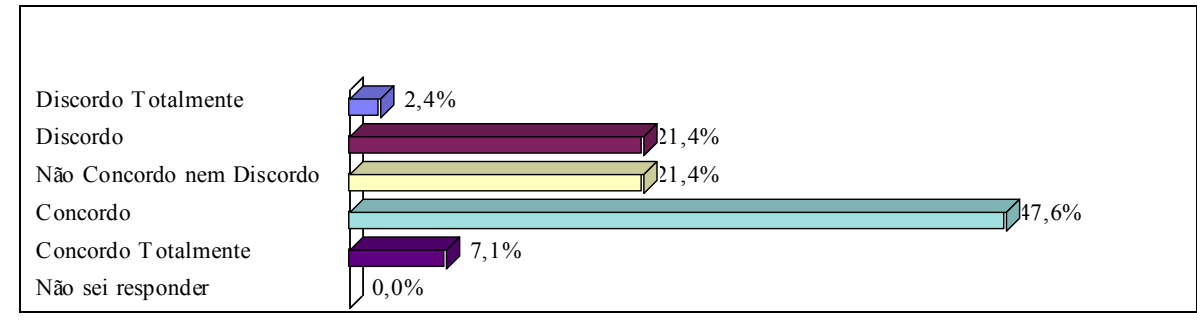

Gráfico 1 Concordância quanto as estratégias serem alinhadas com a missão e visão Fonte: Pesquisa Descritiva Quantitativa, 2009. 
$\mathrm{Na}$ análise da escala de concordância a média de respostas ficou em 3,36, a qual pende para uma leve concordância, porém é fácil observar a divergência nas respostas. O desvio padrão encontrado nestas respostas é 0,98 , o que significa que no grupo há uma significativa heterogeneidade nas respostas, ou seja, as pessoas não pensam da mesma forma.

Esses resultados apresentados corroboram com as respostas das entrevistas, quando estes divergem na opinião da existência do alinhamento das estratégias com a missão e visão da Universidade.

Focando uma análise sobre se: as estratégias definidas para a instituição são claramente disseminadas e entendidas em todos os níveis da organização, os respondentes apontaram a seguinte concordância, demonstrada no gráfico 2:

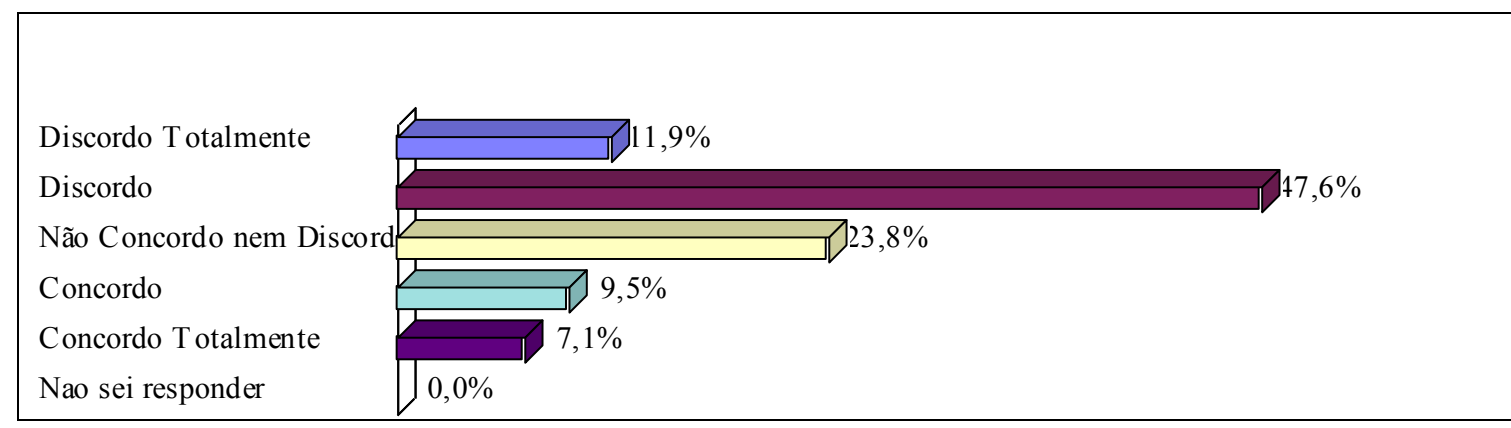

Gráfico 2 Concordância quanto a disseminação e entendimento das estratégias na instituição Fonte: Pesquisa Descritiva Quantitativa, 2009

Existe discordância da grande maioria quanto a disseminação e entendimento das estratégias na organização. A média de respostas é de 2,52 e o desvio padrão de 1,06. Esta informação remete a falha de comunicação existente na instituição.

Kaplan e Norton (1997) dizem que a comunicação do BSC em todos os níveis organizacionais são essenciais para que o modelo integrado de gestão tenha sucesso, portanto na ocasião da implantação do BSC na Universidade, este fato precisará ser observado e atribuída especial atenção.

Caso a universidade não cultue a gestão envolvendo as pessoas da organização, acarretará em uma limitação para a aplicação do BSC na IES.

A análise seguinte foca na necessidade de ter estas formulações de estratégias alinhadas com a missão e a visão na universidade e o porquê da necessidade.

A análise de conteúdo aponta que há unanimidade das respostas na opinião dos entrevistados quanto a necessidade da universidade ter estratégias alinhadas a missão e visão. É perceptível o consenso e/ou a aceitação do fato por todos os gestores. 
A compreensão das informações colocadas pelos entrevistados é de que todos os componentes da alta gestão consideram necessárias as estratégias alinhadas com a missão e visão para a gestão da IES, tornando uma possibilidade para a aplicação do BSC.

Sobre a importância de a instituição possuir gestão estratégica por indicadores de desempenho os gestores estratégicos apontaram sua opinião unânime à concordância de que indicadores são importantes para a gestão da universidade. Quando analisadas junto com as respostas dos gestores táticas a importância é ditada por um percentual de 90,4\% de concordância quanto a importância de a universidade ter essa gestão.

Os indicadores prioritários e mais citados são os da perspectiva de aprendizado e crescimento (pessoas), seguido pelos da perspectiva financeira.

Kaplan e Norton (1997) explicam que os resultados financeiros só serão alcançados se houver pessoas motivadas, qualificadas e produtivas na organização. Isto mostra coerência nas respostas dadas pelos gestores na visão de gestão para a Universidade.

Diante disso se caracteriza mais uma possibilidade para a aplicação do BSC.

Quanto a análise da situação sobre a gestão estratégica da instituição, focando na mensuração/avaliação do desempenho das estratégias, mais de 50\% dos respondentes discordam da existência de um processo formal de mensuração do desempenho na instituição. A média ponderada das respostas é de 2,56, o que confirma a tendência para a discordância dessa afirmação.

Compreende-se de forma geral que a universidade necessita de uma formalização sobre as estratégias e sua respectiva avaliação e/ou mensuração. Isto torna oportuna a aplicação do BSC na instituição, pois o modelo de gestão BSC, proporciona o desdobramento da estratégia em indicadores de desempenho que permitem a mensuração do resultado e a avaliação da eficácia da ação (KAPLAN; NORTON, 2000).

\subsubsection{Compreensão das informações futuras e situacionais para proposição das diretrizes para aplicação do BSC}

As informações coletadas na pesquisa para uma futura aplicação do BSC estão inteiramente relacionadas a sua teoria, principalmente no que reflete a sua estruturação. Portanto as abordagens realizadas aos entrevistados e aos respondentes dos questionários estão voltadas as quatro perspectivas do BSC (financeiras, clientes, processos internos e aprendizado e crescimento). 
Na sequência estão apresentadas no quadro 1 as respostas dos entrevistados, sobre os indicadores que consideram importantes para a composição (informações futuras) em cada uma das perspectivas do BSC para a universidade. Verifica-se no quadro 1 as perspectivas, os indicadores mais citados e a quantidade de vezes que foram mencionados pelos entrevistados.

\begin{tabular}{|c|c|c|c|c|c|c|c|}
\hline \multicolumn{2}{|c|}{ Perspectiva Financeira } & \multicolumn{2}{|c|}{ Perspectiva Clientes } & \multicolumn{2}{|c|}{$\begin{array}{c}\text { Perspectiva Processos } \\
\text { Internos }\end{array}$} & \multicolumn{2}{|c|}{$\begin{array}{l}\text { Perspectiva } \\
\text { Aprendizado e } \\
\text { Crescimento }\end{array}$} \\
\hline $\begin{array}{c}\text { Indicadores } \\
\text { Mencionados }\end{array}$ & $\begin{array}{l}\text { Qtde de } \\
\text { Citações }\end{array}$ & $\begin{array}{l}\text { Indicadores } \\
\text { Mencionados }\end{array}$ & $\begin{array}{l}\text { Qtde de } \\
\text { Citações }\end{array}$ & $\begin{array}{l}\text { Indicadores } \\
\text { Mencionados }\end{array}$ & $\begin{array}{l}\text { Qtde de } \\
\text { Citações }\end{array}$ & $\begin{array}{c}\text { Indicadores } \\
\text { Mencionados }\end{array}$ & $\begin{array}{l}\text { Qtde de } \\
\text { Citações }\end{array}$ \\
\hline Sustentabilidade & 16 & Satisfação & 09 & $\begin{array}{c}\text { Padronização } \\
\text { das } \\
\text { informações e } \\
\text { dos sistemas }\end{array}$ & 08 & Qualificação & 21 \\
\hline Orçamento & 10 & Retenção & 04 & Comunicação & 06 & $\begin{array}{l}\text { Plano de } \\
\text { Carreira } \\
\end{array}$ & 06 \\
\hline Superávit & 10 & Fidelização & 04 & $\begin{array}{l}\text { Demanda de } \\
\text { cursos }\end{array}$ & 05 & $\begin{array}{l}\text { Avaliação de } \\
\text { desempenho }\end{array}$ & 06 \\
\hline $\begin{array}{l}\text { Ponto de } \\
\text { Equilíbrio }\end{array}$ & 03 & $\begin{array}{c}\text { Acompanhamento } \\
\text { do egresso }\end{array}$ & 04 & Produtividade & 06 & $\begin{array}{c}\text { Clima } \\
\text { Organizacional }\end{array}$ & 06 \\
\hline Inadimplência & 02 & $\begin{array}{c}\text { Perfil e } \\
\text { prospecção } \\
\text { de alunos }\end{array}$ & 03 & $\begin{array}{l}\text { Estrutura } \\
\text { hierárquica }\end{array}$ & 05 & $\begin{array}{l}\text { Benefícios e } \\
\text { descrição de } \\
\text { cargos }\end{array}$ & 04 \\
\hline
\end{tabular}

Quadro 1 Indicadores mencionados pelos entrevistados para a composição futura das quatro perspectivas do BSC.

Fonte: Pesquisa exploratória, 2009.

As informações coletadas dos gestores estratégicos, contidas no quadro 1, para compor as quatro perspectivas do BSC, corroboram em sua maioria com a teoria sobre medidas essenciais colocadas por Kaplan e Norton (1997, 2000). Todas as informações tornam possível a formulação das perspectivas do BSC em uma futura implementação.

A perspectiva aprendizado e crescimento é a que tem maior necessidade de complementação, pois nas informações concedidas pelos gestores não estão contempladas a satisfação e retenção dos colaboradores nem tão pouco sua produtividade, as quais são consideradas como essências por Kaplan e Norton.

Devido as organizações com atividades de educação possuírem objetivos complexos e por esta característica adotarem uma multiplicidade de critérios de estruturação, e ainda pela forte percepção identificada nas entrevistas onde os respondentes indicam questões legais para a gestão da universidade em questão, levou a ser considerada nesta pesquisa a formulação de mais uma perspectiva além das quatro identificadas no BSC, denominada perspectiva legal. 
Os indicadores mais citados para a composição da perspectiva legal foram: Lei de Diretrizes e Bases - LDB, SINAES e Conselho Estadual de Educação.

Niven (2005) cita que se a organização percebe que as quatro perspectivas do BSC não são suficientemente amplas para capturar a maioria dos seus elementos, deve pensar em acrescentar uma perspectiva diferente a este grupo.

No sentido de verificar a situação das quatro perspectivas na instituição foi identificado, pelo questionário aplicado, se os gestores concordam sobre a existência de uma definição de estratégias focadas na eficiência de cada uma das perspectivas da instituição bem como se há mensuração de seu desempenho.

A primeira análise indicada nos dados dos gráficos $3,4,5$ e 6 , são sobre a concordância dos gestores estratégicos e táticos da instituição sobre a existência de estratégias na eficiência financeira, dos clientes, dos processos internos e do aprendizado e crescimento.

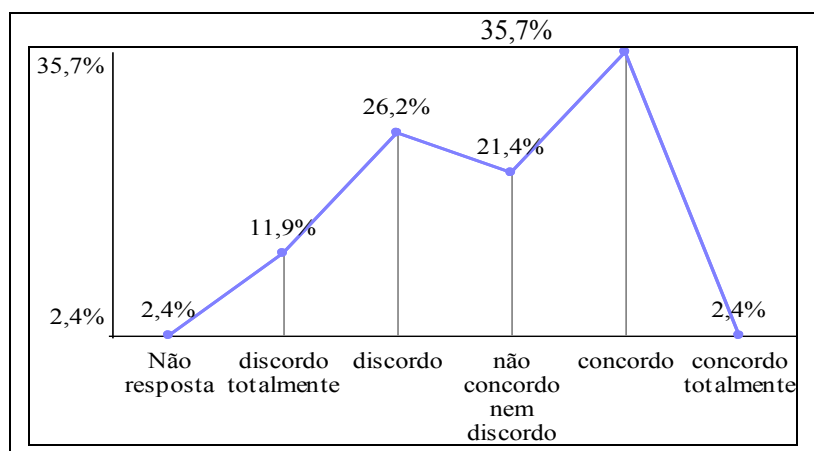

Gráfico 3 Concordância quanto a existência de estratégias e ações financeiras na instituição Fonte: Pesquisa Descritiva Quantitativa, 2009

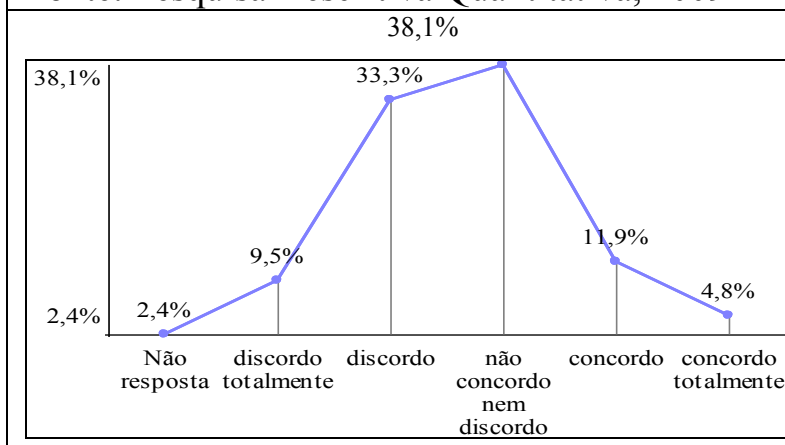

Gráfico 5 Concordância quanto a existência de estratégias e ações focadas nos processos internos da instituição

Fonte: Pesquisa Descritiva Quantitativa, 2009

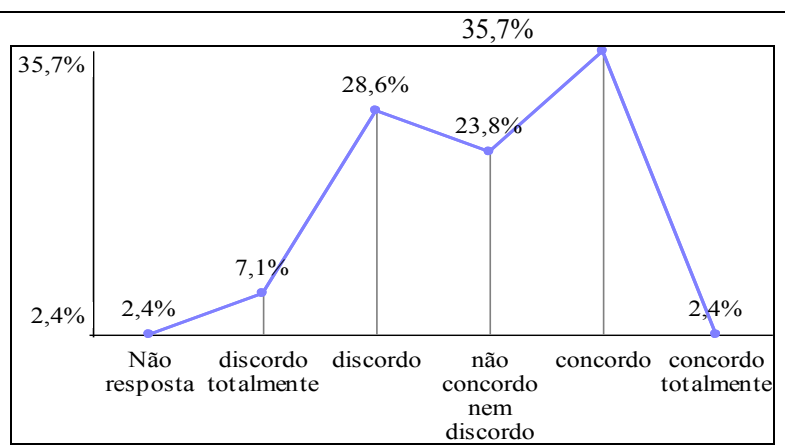

Gráfico 4 Concordância quanto a existência de estratégias e ações focadas nos clientes/alunos Fonte: Pesquisa Descritiva Quantitativa, 2009

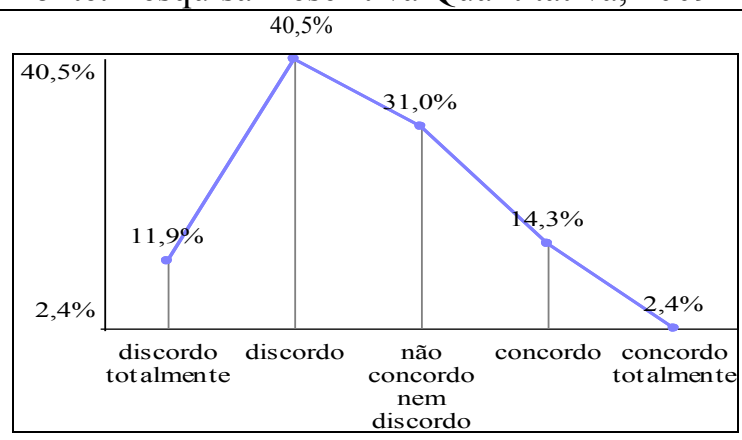

Gráfico 6 Concordância quanto a existência de estratégias e ações focadas a pessoas da instituição

Fonte: Pesquisa Descritiva Quantitativa, 2009

Os gráficos evidenciam que os gestores da instituição tendem a discordância quanto a existência da definição de estratégias claras para cada uma das perspectivas do BSC. Numa 
análise estatística por média ponderada da escala de Likert, a perspectiva de clientes é a que obteve maior média, sendo de 2,98. A perspectiva financeira obteve uma média ponderada de 2,90, a de processos internos de 2,68 e de aprendizado e crescimento de 2,55.

A predominante discordância apresentada sobre a existência das estratégias nas perspectivas do BSC é considerada aqui como uma situação favorável para a aplicação modelo de gestão na instituição, pela forma de gestão que irá proporcionar, ocasionando uma clareza na definição das estratégias.

Os gráficos 7, 8, 9 e 10 indicam a situação da gestão da universidade, quanto a mensuração das estratégias.

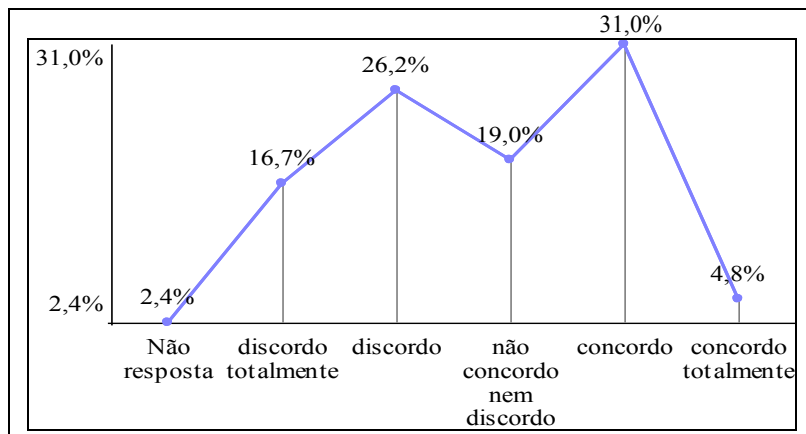

Gráfico 7 Concordância quanto a existência da mensuração do desempenho financeiro da instituição

Fonte: Pesquisa Descritiva Quantitativa, 2009

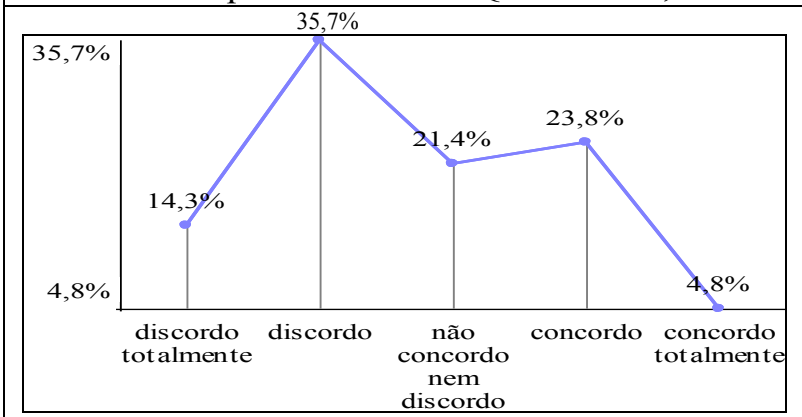

Gráfico 9 Concordância quanto a existência da mensuração do desempenho das ações focadas nos processos internos da instituição Fonte: Pesquisa Descritiva Quantitativa, 2009

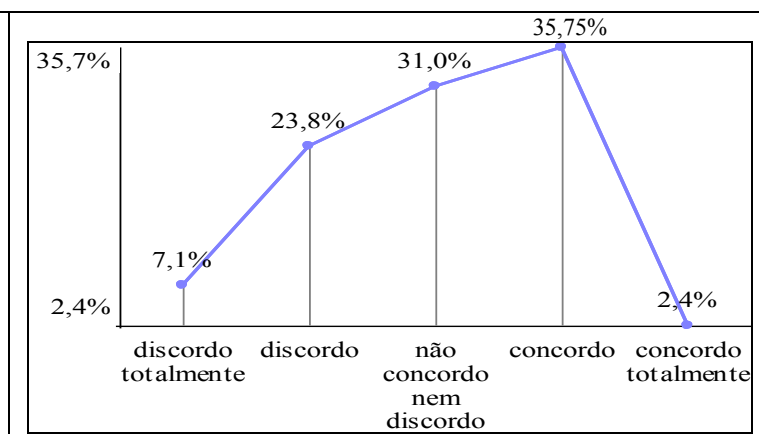

Gráfico 8 Concordância quanto a existência da mensuração do desempenho das ações focadas nos clientes/alunos da instituição Fonte: Pesquisa Descritiva Quantitativa, 2009

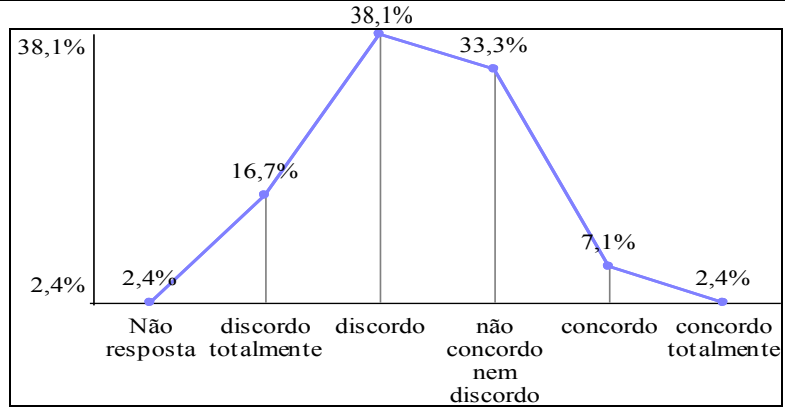

Gráfico 10 Concordância quanto a existência da mensuração do desempenho das ações focadas nas pessoas da instituição

Fonte: Pesquisa Descritiva Quantitativa, 2009

Conforme os dados obtidos e apresentados nos quatro últimos gráficos, os gestores da universidade, em sua maioria não percebem estratégias nem tão pouco suas respectivas mensurações nas quatro perspectivas do BSC, o que torna possível a aplicação do BSC pela forma de gestão que irá proporcionar. 
As médias ponderadas calculadas sobre a concordância da existência de mensuração das estratégias são: perspectiva financeira de 2,80, perspectiva de clientes 3,02 , perspectiva de processos internos de 2,69 e da perspectiva de aprendizado e crescimento de 2,39.

A situação sobre mensuração de estratégias traz mais uma possibilidade para aplicação de um modelo de gestão direcionado ao estabelecimento de estratégias e sua respectiva mensuração. Kaplan e Norton (1997) afirmam que o estabelecimento de formas para acompanhamento das estratégias, onde se possa avaliar e mensurar sua execução é fundamental para um desempenho positivo de organizações.

\subsubsection{Oportunização para a aplicação do BSC na IES}

A análise desta categoria temática concerne a aceitação dos gestores estratégicos de uma futura implementação do BSC na instituição. Tais gestores consideram de forma unânime a aceitação quanto a aplicação do referido modelo de gestão.

Vale observar que a maioria dos entrevistados deixou claro que além de achar oportuna a aplicação do BSC, também que isto seja realizado quando a gestão dos cinco campi da Universidade seja unificada, pois atualmente ages tão ocorre de forma autônoma em cada Campus.

A oportunização para a aplicação do BSC incluindo a opinião dos gestores táticos está representada no gráfico 11:

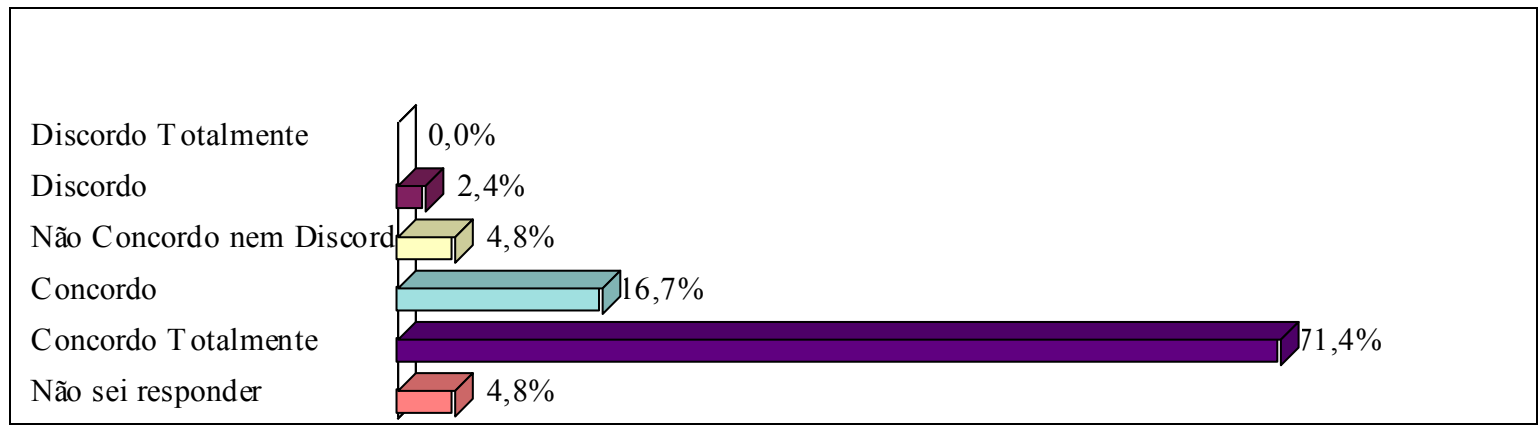

Gráfico 13 Concordância se um modelo de gestão integrada pode melhorar o desempenho Fonte: Pesquisa Descritiva Quantitativa, 2009

Há concordância dos respondentes pela representatividade da soma entre as escalas de concordância de $88,10 \%$. A média de 4,67 confirma . O desvio padrão é de 0,69 . Portanto se torna oportuna a aplicação do BSC mediante o fato de a grande maioria dos gestores concordarem que este modelo de gestão pode melhorar o desempenho da instituição. 
Esse quesito é dos principais itens da pesquisa a ser considerado como possibilidade de aplicação do BSC, desde que as pessoas que o consideram necessário e importante se comprometam com o modelo de gestão, pois segundo Costa (2006, p. 57) "[...o BSC não deve ser implantado [...] sem a garantia do comprometimento da alta administração e dos gerentes de linha."

\subsection{Proposta das diretrizes para aplicação do BSC para a IES}

A elaboração de uma proposta com as diretrizes para a aplicação do BSC para a universidade teve como base os resultados das três pesquisas realizadas - bibliográfica, documental e de campo.

Da pesquisa bibliográfica foi utilizado o plano típico e sistemático de Kaplan e Norton (1997) que refere-se aos seguintes passos: definição da arquitetura de indicadores; consenso em função dos objetivos estratégicos, escolha e elaboração de indicadores e elaboração do plano de implementação, conforme apresentadas no quadro 2, estruturada com a base teórica e qual diretriz está a ela relacionada.

\begin{tabular}{|c|c|}
\hline Base teórica do BSC & Diretriz para aplicação na IES \\
\hline $\begin{array}{l}\text { Definição da Arquitetura de } \\
\text { Indicadores }\end{array}$ & A mantenedora da IES ser unificada \\
\hline \multirow{5}{*}{$\begin{array}{l}\text { Consenso em Função dos } \\
\text { Objetivos Estratégicos }\end{array}$} & $\begin{array}{l}\text { Possuir missão e visão } \\
\end{array}$ \\
\hline & $\begin{array}{l}\text { Ser detentora de uma análise de informações sobre o ambiente da } \\
\text { Instituição }\end{array}$ \\
\hline & $\begin{array}{c}\text { Definir Fatores Chaves de Sucesso e Temas Estratégicos para cada } \\
\text { perspectiva do BSC }\end{array}$ \\
\hline & Preparar um rol de objetivos estratégicos preliminares \\
\hline & Identificar objetivos para cada perspectiva do BSC \\
\hline \multirow[t]{2}{*}{$\begin{array}{l}\text { Escolha e Elaboração dos } \\
\text { Indicadores }\end{array}$} & $\begin{array}{l}\text { Escolher e definir indicadores de desempenho essenciais para cada } \\
\text { objetivo estratégico numa relação de causa e efeito, buscando } \\
\text { indicadores que melhor comuniquem o significado da estratégia }\end{array}$ \\
\hline & Comunicar as intenções e o conteúdo do scorecard. \\
\hline \multirow{6}{*}{$\begin{array}{l}\text { Elaboração do Plano de } \\
\text { Implementação }\end{array}$} & Desenvolver o Plano de Implementação \\
\hline & $\begin{array}{l}\text { Obter decisão final sobre a visão, os objetivos e indicadores; e, } \\
\text { identificação de programação de ações para alcançar as metas }\end{array}$ \\
\hline & Comunicar os scorecards em todos os níveis da instituição \\
\hline & Integrar os scorecards à filosofia gerencial \\
\hline & Desenvolver sistemas de informações que sustente o scorecard \\
\hline & $\begin{array}{l}\text { Elaborar um cronograma de implementação para consolidação do } \\
\text { scorecard }\end{array}$ \\
\hline
\end{tabular}

Quadro 2 Diretrizes para aplicação do BSC na IES

Fonte: Adaptado de Kaplan e Norton (1997) 
A partir das diretrizes identificadas neste tópico, os gestores da universidade, podem aplicar o scorecard como modelo de gestão integrada na instituição, mediante análises atualizadas no momento da aplicação. Lembrando que estas diretrizes devem ser entendidas como uma proposta e não como uma obrigatoriedade.

\section{CONCLUSÃO}

Conclui-se que o modelo de gestão BSC pode ser aplicado na universidade em questão desde que haja adaptações do modelo para com a realidade organizacional da instituição.

A identificação das diretrizes existentes na Universidade para a implementação do BSC, são a missão e visão corporativa, e um conjunto de informações sobre o ambiente em que a IES está inserida. A existência dessas diretrizes preliminares existentes apresenta mais uma possibilidade de aplicação do modelo de gestão.

A compreensão das informações identificadas dos gestores da Universidade, concluise que a maioria dos gestores da Universidade entendem consideravelmente sobre formulação de estratégias alinhadas a missão e a visão, porém há uma disparidade de opiniões quanto a existência deste alinhamento na Universidade. Os gestores as consideram necessárias e importantes na gestão da universidade. Os gestores não percebem a existência de disseminação e entendimento da estratégia em todos os níveis hierárquicos da instituição.

Das descrições anteriores, o único fator da análise que torna uma limitação para aplicação do BSC é quanto a disseminação e entendimento da estratégia em todos os níveis da organização. A falta de disseminação reflete a ineficiência da comunicação dentro da instituição.

Os indicadores mencionados pelos gestores para uma futura composição do BSC para a universidade estão de acordo com aqueles colocados pela teoria do método. A única perspectiva que necessitará de complementações é a de aprendizado e crescimento.

Faz-se necessária a adaptação de uma perspectiva ao modelo do BSC para essa universidade que é a perspectiva legal, mediante as diversas menções feitas pelos seus gestores estratégicos quanto a preocupação com as regulações legislativas que a universidade deve proceder.

Numa análise situacional quanto a existência de estratégias em cada uma das perspectivas do BSC e de suas respectivas mensurações, os gestores tendem a discordância, ou seja, os gestores não percebem as estratégias nem tampouco uma avaliação do desempenho delas. Esse fato mostra uma possibilidade para a aplicação do BSC. 
A aceitação dos gestores da aplicação do modelo de gestão é unanime quando considerada somente a opinião dos gestores estratégicos e muito alta quando adicionada a opinião dos gestores táticos. Portanto esse fator é o que proporciona maiores possibilidades de aplicação do modelo de gestão.

Conclui-se ainda que as diretrizes propostas para a aplicação do BSC na universidade, totalizando 14, são suficientes e proporcionam um caminho trilhado na teoria e nos resultados da pesquisa bibliográfica. Portanto podem ser aplicadas mediante uma revisão dos gestores desta instituição.

Numa visão geral deste trabalho de pesquisa, é possível concluir que o estudo realizado na universidade aponta mais possibilidades do que limitações para a aplicação do BSC, afirmando a possibilidade de sua aplicação na Fundação Mantenedora, desde que sejam consideradas as características peculiares da instituição. Porém, está distante de abordar toda a complexidade de ações e informações para sua aplicação.

Quando analisado o trabalho numa visão teórica mais ampla, é possível concluir que o mesmo adiciona ao campo teórico de gestão em IES. Porém é importante considerar, que ainda há um amplo campo de pesquisa a ser desenvolvido nesta área tão proveitosa que diz respeito à administração de organizações como as IES, que impregna função e responsabilidade tão significante para a sociedade e seu desenvolvimento.

\section{REFERÊNCIAS}

ALMEIDA, Edson Pacheco de. A universidade como núcleo de inteligência estratégica. In: MEYER JUNIOR, Victor; MURPHY, Patrick. Dinossauros, gazelas \& tigres: novas abordagens da administração universitária. Florianópolis: Insular, 2003.

BALDRIDGE, J Victor. Organizational characteristics of colleges and universities. In: BALDRIDGE, J. Victor; DEAL, Terence (Ed.). The dynamics of organizational change in education. Berkeley: McUtchan, 1983.

BARDIN, Laurence. Análise de conteúdo. Lisboa: Ed. 70, 1979.

BEUREN, Ilse Maria. Como elaborar trabalhos monográficos em contabilidade: teoria e prática. São Paulo: Atlas, 2006.

BIRNBAUM, R. .How colleges work. San Francisco: ]ossey-Bass, 1988

BRASIL. Lei de diretrizes e bases da educação nacional. Lei n ${ }^{\circ}$ 9.394, de 20 de dezembro de 1996. Estabelece as diretrizes e bases da educação nacional. Disponível em:

<ftp://ftp.fnde.gov.br/web/siope_web/lei_n9394_20121996.pdf>. Acesso em: 03 jan. 2009. 
BRYSON, John M. Strategic planing for public and monoprofit organizations. 3.ed. San Francisco: Jossey-Bass, 2004.

BRYSON, John M.; ALSTON, Farnum K. Creating an implementing your strategic plan. San Francisco: Jossey Bass, 1996.

CAVALIERI, Adriane; MACEDO-SOARES, T. Diana L. V. A de; THIOLLENT, Michel. Avaliando o desempenho da universidade. São Paulo: Loyola, 2004.

COHEN, Michael D.; MARCH, James G. Leadership and ambiguity. Boston: Harvard Business Scholl Press, 1974

COSTA, Ana Paula P. Balanced Scorecard: conceitos e guia de implementação. São Paulo: Atlas, 2006

FERNANDES, Bruno H. R.; BERTON, Luiz Hamilton. Administração estratégica: da competência empreendedora à avaliação de desempenho. São Paulo: Saraiva, 2005

GIL, Antonio Carlos. Como elaborar projetos de pesquisa. São Paulo: Atlas, 2002.

HAIR, JR. et al. Fundamentos de métodos de pesquisa em administração. São Paulo: Bookman, 2005.

HARDY, Cynthia; FACHIN, Roberto. Gestão estratégica na universidade brasileira: teoria e casos. Porto Alegre: Ed. da UFRGS, 2000.

HERRERO FILHO, Emilio. Balanced Scorecard e a gestão estratégica: uma abordagem prática. Rio de Janeiro: Campus, 2005.

KAPLAN, Robert; NORTON David. A estratégia em ação: balanced scorecard. Rio de Janeiro: Campus, 1997. ; . Organização orientada para a estratégia. Rio de Janeiro: Campus, 2000.

KELLER, G. Academic strategy: the management revolution in american higher education. Baltimore: The Johns Hopkins University Press, 1983

MANGELS, Mathias. Prefácio. In: HERRERO FILHO, Emilio. Balanced Scorecard e a gestão estratégica. Rio de Janeiro: Campus, 2005.

MALHOTRA, Naresh K. Pesquisa de marketing: uma orientação aplicada. Porto Alegre: Bookman, 2001.

MEYER JR. Victor, A Escola como organização complexa. In: EYNG, Ana Maria; GISI, Maria Lourdes. Políticas e gestão da educação superior. São Paulo. Editora UNIJUI, 2007

MEYER JR. Victor; LOPES, Maria Cecília Barbosa. Gestión escolar: desafios y alternativas gerenciales. Visiones da La educación n. 13: 55-65, Primer Semestre, 2008 
MINTZBERG, Henry et al. O processo da estratégia: conceitos, contextos e casos selecionados. Porto Alegre: Bookman, 2008.

MORGAN, Gareth. Imagens da organização. São Paulo: Atlas, 1996.

NIVEN, Paul R. Balanced Scorecard passo-a-passo: elevando o desempenho e mantendo resultados. Rio de Janeiro: Qualitymark, 2005.

PEREIRA, Mauricio F.; MELO, Pedro A.; CUNHA, Myriam S. A história e a experiência da Universidade Federal de Santa Catarina com o processo de planejamento estratégico. In: DOMINGUES, Maria José C. S.; SILVEIRA, Amélia. Gestão de ensino superior: temas contemporâneos. Blumenau: Edifurb, 2008.

RICHARDSON, Roberto Jarry. Pesquisa social: métodos e técnicas. São Paulo: Atlas, 1999.

SPHINX. Software para Coleta, Análise e Pesquisa de Dados, 2007.

WEICK, Karl E. Educational Organizations as loosely coupled systems. Administrative science quarterly. Vol. 21, n.1, mar/1976. Johnson Graduate School of Management: Cornel University, 1976. 